\title{
Students' evaluation of a computerized patient simulator in nursing education and its effect on the results of preclinical tests
}

\author{
Elisabeth K. Flaathen, Jill Flo , Lisbeth Fagerström \\ Faculty of Health Sciences, Institute of Nursing Science, Buskerud and Vestfold University College, Drammen, Norway
}

Received: February 4, 2015

Accepted: March 19, 2015

Online Published: April 16, 2015

DOI: $10.5430 /$ jnep.v5n7p1

URL: http://dx.doi.org/10.5430/jnep.v5n7p1

\begin{abstract}
The aim of the study was two-fold: to evaluate nursing students' experiences of active participation in the use of a-computerized simulation manikin during preclinical first-year Bachelor's studies, and to evaluate the effect of active participation in simulation by comparing active students' result with observers' result on preclinical test. An evaluative case study design was used to evaluate simulation with a computerized manikin as a pedagogical learning method. A questionnaire was used to evaluate the active students' experiences. The second part was a comparison between the active students' and the observers' preclinical test results. Findings indicated that the students thought simulation was beneficial, feedback from peers and lecturer was helpful and reflection during debriefing was beneficial. A significant difference was seen between those students who actively participated and those who observed in relation to the pass/fail preclinical test. Nursing students experienced simulation with a computerized manikin as being a beneficial pedagogical learning method, and active participation in a simulation situation can help students pass their preclinical test.
\end{abstract}

Key Words: Simulation, Students' experiences, Nursing education, Preclinical test

\section{INTRODUCTION}

The use of simulation has increased in nursing education over the last twenty years, and today simulation with computerized patient simulators (also called Human Patient Simulator (HPS) or high-fidelity simulation) is used in nursing education both in Norway and internationally. ${ }^{[1-10]}$

The use of simulation manikins is recognized as being a safe training method for students. ${ }^{[1]}$ According to Harder, ${ }^{[12]}$ high-fidelity simulation increases students' practical skills. Today technology is increasingly used in health care, and training practical skills with computerized manikins can support and facilitate the development of students' knowledge and practical skills. ${ }^{[13,14]}$ There is also an increasing demand for clinical placements and supervision in the clinical field, and by using simulation more effectively practical training in clinical fields may be shortened. Still, simulation can never replace clinical studies and must remain a complementary method of education. It is important to have a critical approach to what simulation in the laboratory can offer. ${ }^{[15]}$

In one study, Alinier et al. ${ }^{[1]}$ determined that simulation based training is beneficial and can provide an opportunity for training undergraduate nursing students. No differences were seen between the confidence and performance levels of nursing students receiving simulation training in an experimental group versus a control group who used more traditional educational techniques. A study by Gates, Parr

\footnotetext{
*Correspondence: Jill Flo; Email: Jill.Flo@hbv.no; Address: Faculty of Health Sciences, Institute of Nursing Science, Buskerud and Vestfold University College, Drammen, Norway. 
and Hughen ${ }^{[16]}$ indicated that students benefit from participation in high-fidelity simulation and found a more than $8 \%$ increase in examination performance. Such studies show that participation in simulation can be used as a viable educational method in clinical training. According to Lewis, Strachan and Smith ${ }^{[17]}$ participating in high-fidelity simulation seems to help students learn from mistakes and even prevent future mistakes.

A study by Rhodes and Curran ${ }^{[18]}$ revealed that students experience simulation as being positive, but that they did not like role-play. That students feel safe in a situation is important for learning. Feeling some nervousness can be positive for learning, but too much anxiety negatively affects learning. ${ }^{[19]}$ Some students feel awkward being videotaped during simulation. ${ }^{[20,21]}$ Why some students are nervous or uncomfortable being observed in a simulation situation may be related to what Bandura ${ }^{[22]}$ terms self-efficacy, which is the measure of a person's belief in his/her own ability to master a specific task. A relationship exists between self-efficacy and work-related skills. The higher self-efficacy a person has the better their employability.

This study was a continuation of an evaluative case study of students' experiences of learning through the use of a computerized simulation manikin in preclinical studies. ${ }^{[23]}$ In Norway, nursing education is regulated by the Act Relating to Universities and University Colleges ${ }^{[24]}$ and steered by the national Curriculum Framework for Nursing Education. ${ }^{\text {[25] }}$ In 2002, a new educational degree structure including Bachelor's and Master's degrees was introduced. ${ }^{[26]}$ In accordance with an EU directive from 2005, ${ }^{[27]}$ practical studies and skill training are mandatory and comprise $50 \%$ of the study program.

\subsection{Background}

In 2010, Buskerud and Vestfold University College introduced computerized simulation into its first-year Bachelor's nursing studies. Attendance during the degree program's preclinical studies is mandatory, and the preclinical studies culminate in a test graded on a pass/fail basis.

The Curriculum for Preclinical Studies used during the program's preclinical second semester studies provided the foundation for the establishment of learning goals for simulation situations. The learning goals were presented via the University College's digital learning platform so that all students could arrive prepared for a simulation. The main learning goals were:

- To evaluate various patient situations, plan and implement a patient's nursing care.

- To recognize each human being's uniqueness and dig- nity.

- To apply the principles of nursing documentation.

Each main goal also encompassed diverse sub-goals, for example that students are capable of inserting an indwelling urinary catheter. A computerized simulation manikin manufactured by Laerdal Medical called Nursing Anne was used for simulation situations and two scenarios were developed and implemented.

\subsection{Preclinical test}

Before the students allowed to start their clinical studies, they had to pass the preclinical test that took about 60 minutes to complete. During their preclinical studies, the students were trained in all of the procedures that may appear on the test. During the test a student was randomly assigned a procedure and had to implement it and answer relevant questions, with the task being presented as a patient case. To pass, the procedure had to be performed in the correct way and the student had to demonstrate appropriate patient and personal safety while also respecting the patient's integrity. Students were immediately informed of whether they had passed or failed the test.

\subsection{Aim}

The aim of the study was two-fold: to evaluate nursing students' experiences of active participation in the use of a computerized simulation manikin during first-year Bachelor's studies and to evaluate the effect of active participation in simulation by comparing active students' results with observers' results on the preclinical test. Students' experiences were defined as students' perceptions of and opinions on the use of simulation in nursing education.

\section{MATERial AND METHODS}

\subsection{Design}

The study had an evaluative case study design. This evaluation study consisted of two parts. The first part was an evaluation of the active students' experiences of active participation in the use of a computerized simulation manikin through a questionnaire. The second part was a comparison between the active students' and the observers' preclinical test results.

\subsection{The description of the simulation scenarios with computerized simulation manikin}

The simulation scenarios of the actual study were inspired by Dieckmanns ${ }^{[28]}$ pedagogical learning method.

The lecturer first planned the simulation scenario, including learning needs, learning objectivities, group size and time frame. Then a short briefing on the scenario in plenum 
followed, lasting about 5 minutes, during which students' queries were addressed. Finally, the two pre-selected active students entered the simulation room and were instructed in use of the equipment, after which the simulation scenario started. This lasted about 20 minutes, followed by a debriefing that lasted about 20 minutes: roughly 40 minutes in total. At the beginning of each debriefing, the two active students described their experiences of the simulation, including what they felt, thought and did in relation to the actions needed for the scenario and also what they felt they could or should do differently. Then the observers gave the active students feedback relevant to teamwork, communication and practical skills. The lecturers acted as facilitators, and helped the students reflect on their experiences of the simulation and provided feedback on the performance of the two active students. The total time needed for four scenarios was about three hours for each group of students.

An instructor provided the voice of the "patient", communicating with the students through a wireless microphone while hidden behind a one-way screen. The manikin was programmed in accordance with a set case scenario, including appropriate respiratory sound, pulse and blood pressure. These case scenarios also included other interventions: insertion of an indwelling urinary catheter, insertion of a peripheral venous catheter and the calculation and administration of medication through intramuscular injection. In this program preclinical studies are mandatory, and the simulation scenarios are considered part of students' preparation for the preclinical test.

During the first day's first scenario, students practiced the insertion of an indwelling urinary catheter, while for the second scenario students practiced intimate hygiene and positioning and moving the patient to ensure a painless procedure. The students also applied and implemented principles of sterile procedure and aseptic technique. During the second day's first scenario, students practiced inserting a peripheral venous catheter and hanging a prepared infusion, while for the second scenario students observed a postoperative patient and administered an analgesic intramuscularly.

\subsection{Participants}

During an 8-day period in spring 2012, a total of 158 students were registered in the first year, and were divided by the lectures into 12 groups. The students in these groups had worked together during first and second term. The groups were allowed two days during which they were required to simulate two scenarios per day, for a total of four scenarios. A total of 96 students $(60.8 \%)$ of 158 actively participated in the four simulation scenarios, while the remaining students, $62(39.2 \%)$ merely observed. Prior to each scenario, the students themselves decided who would actively participate in each simulation, i.e., who would participate in a scenario as a nurse or assistant (hereafter referred to as "active students"), and who would merely observe (hereafter referred to as "observers"). Of the 96 active students, a total of 76 $(79.1 \%)$ responded to the questionnaire.

Three weeks after the simulation situations the students had their preclinical test, with $155(98 \%)$ of 158 participating in the preclinical test.

\subsection{Instrument and data collection}

The questionnaire has been used in an earlier study ${ }^{[23]}$ but was modified for this study. In spring 2012, data were collected through a questionnaire that included eight closeended questions about the simulation day, preparation, implementation and realization of learning goals and three openended questions. A 5-point Likert scale was used for the close-ended questions, with the answer alternatives: very small extent, small extent, moderate extent, great extent and very great extent. Students were also able to comment on the close-ended questions, and any such comments were used to support the research findings. The three open-ended questions included in the questionnaire were:

- What was your experience of being observed by your peers via a video screen?

- Is there anything that you would like to emphasize as being especially good about simulation?

- Do you have any advice for us in regard to what should be improved or done differently?

A lecturer handed out the questionnaire directly after debriefing. The questionnaire was filled in and returned to the lecturer before the students left the classroom, and students could contact the researchers if needed.

\subsection{Method of data analysis}

During statistical analyses of the questionnaire, Predictive Analytics SoftWare (PASW) for Vista was used. The answer alternatives were changed to $1=$ very small extent, 2 $=$ small extent, $3=$ moderate extent, $4=$ great extent and 5 = very great extent. Descriptive statistics, cross tabulation and correlation by use of Spearman's rho, which is recommended when calculating ordinal scale in smaller studies, ${ }^{[29]}$ were used. To calculate correlation between the questions, an index of the general term "pedagogical learning method" was created, consisting of questions 1-3-4-5-6, with each question being weighted equally. The index was correlated with questions 2,7 and 8 .

Inductive content analysis ${ }^{[30,31]}$ was used to analyze the answers to the open-ended questions. After logging all the responses to the various open-ended questions, the researchers 
read all of the answers to obtain a general impression. Each question was then analyzed separately. Categories were grouped under higher order headings to reduce the number of categories and to capture similarities and differences. Open responses from self-completed questionnaires can provide a different perspective on a phenomenon than frequency distribution alone.

Fisher's exact test ${ }^{[32]}$ was used to calculate the differences between the active students and observers in relation to the pass/fail rate of the preclinical test.

\subsection{Ethical consideration}

In Norway the evaluation of an educational program is a natural part of a university's activities, as delineated in the Act Relating to Universities and University Colleges. ${ }^{[24]}$ The heads of the Institute of Nursing Science, Faculty of Health Sciences gave their permission for this study. All electronic processing of personal data is in principal subject to an obligation to report or licensing in Norway. However, according to $§ 7-20$ in the Norwegian regulations relating to the processing of personal data, the Personal Data Act, ${ }^{[33]}$ it is possible to process personal data without reporting it, provided that such occurs under the auspices of the Act Relating to Universities and University Colleges. ${ }^{[24]}$

Information about the study was provided to students early during the spring 2012 semester and before any actual simulation situations occurred, and this same information was also posted on the University College's digital learning platform. In respect to ethical guidelines, voluntary participation in the study and what the data would be used for, information was provided to students verbally on the day of the simulation. At the preclinical test the lecturer did not know if students had been active participants or observers in simulation situations.

\section{RESULTS}

The results are presented as text, tables and figures. Results from questions concerning the same theme are presented in Figures 1 and 2.

\subsection{Results from questionnaire}

Of the 96 active students, 76 (79.2\%) answered the questionnaire. Of these, $85.5 \%$ were female and $6.6 \%$ were male; $7.9 \%$ chose not to answer questions pertaining to gender and/or age. The students were between the ages of 19 and $>50$ (MD 25.3), and 83.4\% were younger than 30 years of age.

The active students $(n=76)$ experienced active participation in simulation situations during preclinical studies to be a positive experience (see Table 1). The Table lists a summary of all responses, and gives a general overview of the results.

Table 1. Student evaluation of active participation in a simulation situation

\begin{tabular}{llll}
\hline Question & Number & Mean & Standard deviation \\
\hline 1. Satisfied with the information & 73 & 4.15 & 3.42 \\
2. Prepared for the day & 76 & 4.43 & 0.701 \\
3. Simulation was beneficial & 76 & 4.3 & 0.754 \\
4. Feedback from peers in plenum was helpful & 76 & 4.49 & 0.674 \\
5. Feedback from lecturer in plenum was helpful & 76 & 4.32 & 0.663 \\
6. Reflection during debriefing was beneficial & 75 & 3.93 & 0.681 \\
7. The day's learning goals were achieved & 74 & 4 & 0.746 \\
8. Met expectations of the day & 75 & 0.87 \\
\hline
\end{tabular}

Most active students answered that they were prepared for the day to a moderate or very great extent $(\mathrm{Q} 2)$. They also thought simulation was beneficial (Q3) and that the learning goals for the day were achieved (Q7) (see Figure 1).

The active students answered that feedback from peers in plenum (Q4) and feedback from lecturer in plenum (Q5) were helpful. Also reflection during debriefing (Q6) was considered beneficial (see Figure 2).

\subsection{Correlation between the various questions}

A close relationship $(0.701 ; p<.01)$ could be ascertained between Q7 (The day's learning goals were achieved) and Q8 (Met expectations of the day). A moderate correlation
$(0.424 ; p<.01)$ is seen between Q7 (The day's learning goals were achieved) and Q1, 3, 4, 5, 6 (which relate to students' satisfaction with the pedagogical learning method). A moderate correlation $(0.469 ; p<.01)$ is also seen between students' satisfaction with the pedagogical learning method and Q8 (Met expectations of the day). No correlation is seen between students' satisfaction with the pedagogical learning method and Q2 (Prepared for the day).

\subsection{Students' experiences of being observed by peers}

In total, 66 active students $(n=76)$ answered the first openended question about their experiences of being observed by peers via a video screen. Here the following three categories 
were emphasized: "positive experience", "uncomfortable" and "negative experience".

In the category "positive experience", students enjoyed the experience of being observed. "Instructive." "They observed me in a good way, they came with good comments."

In the category "uncomfortable", some students were initially negative but became more positive during the simulation situation. "Not as scary as I thought." "Thought this would be scarier. Learned also much more than expected."

In the category "negative experience", only a few students thought that they did not learn anything at all. "Very unpleasant - embarrassing, not positive at all."

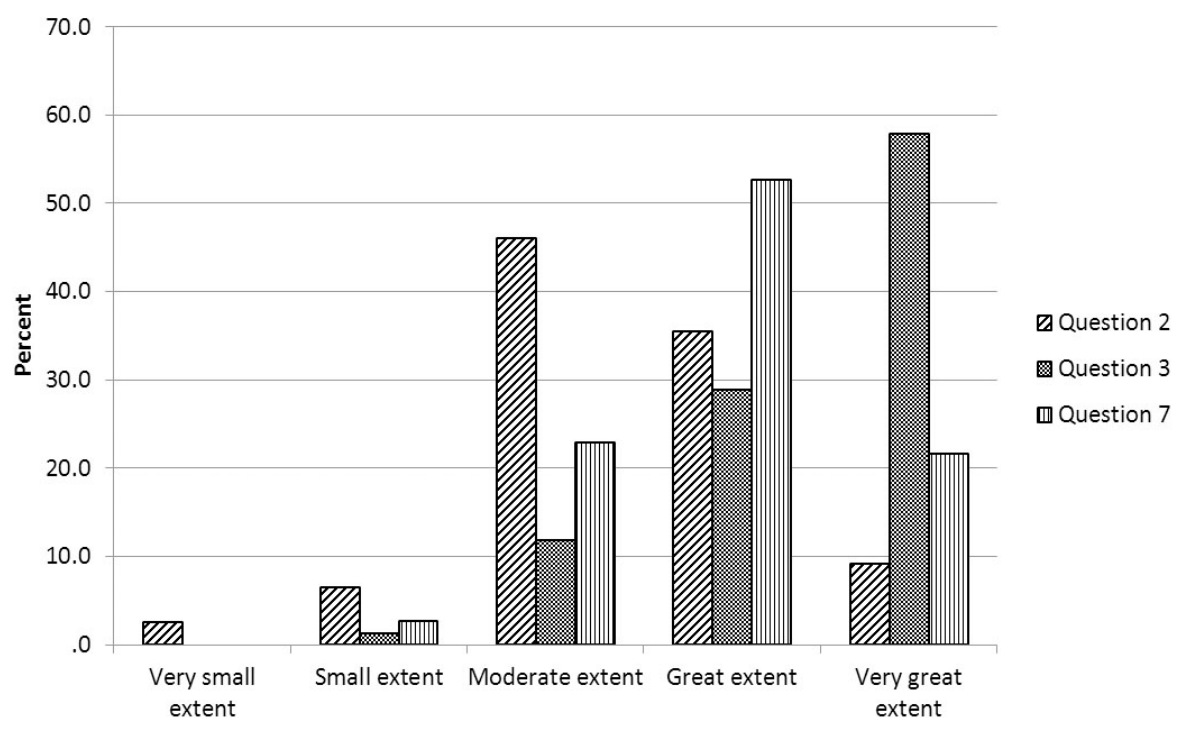

Figure 1. Prepared for the day, Simulation was beneficial and The day's learning goals were achieved Q2: Prepared for the day, Q3: Simulation was beneficial, Q7: The day's learning goals were achieved.

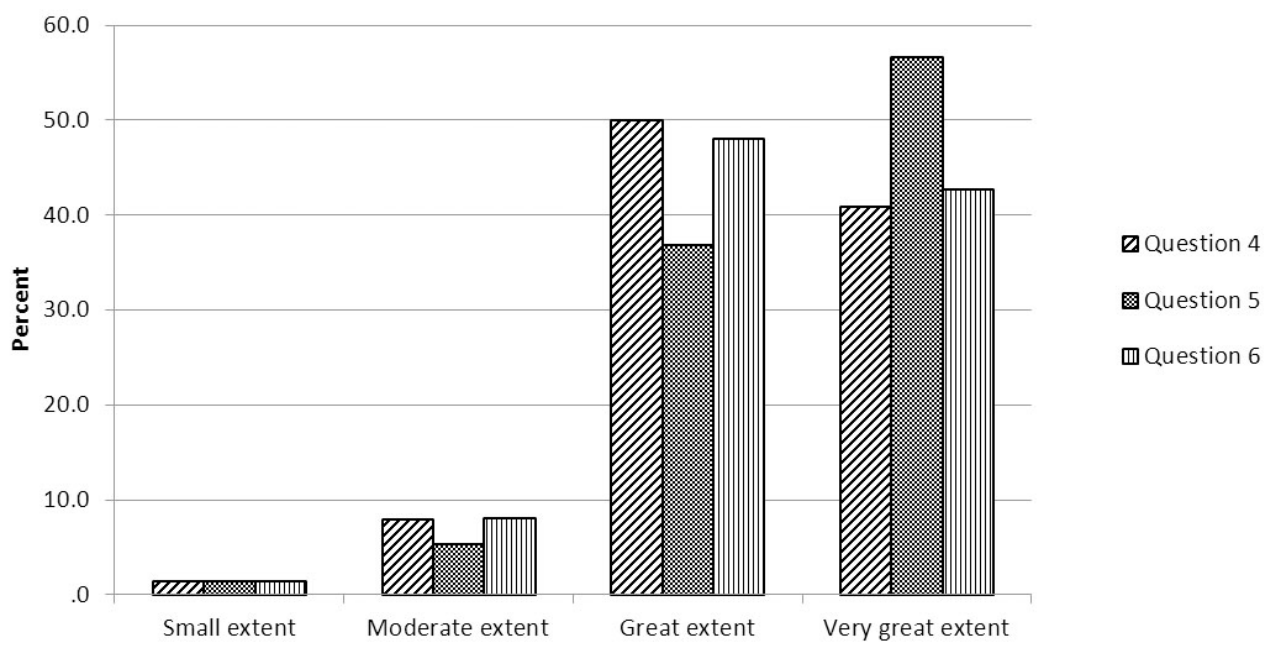

Figure 2. Feedback from peers, Feedback from lecturer and Reflection Q4: Feedback from peers in plenum was helpful, Q5: Feedback from lecturer in plenum was helpful, Q6: Reflection during debriefing was beneficial.

\subsection{Simulation as pedagogical learning method}

Fifty-eight active students $(\mathrm{n}=76)$ answered the second openended question about what they would like to emphasize as being especially good about simulation. The following four categories were emphasized here: "learning", "preparation for test", "recall errors" and "feedback". In the category "learning", many students expressed that they learned a lot during a simulation. "Developmental, both personally and professionally." "Very good teaching, should be used much more." 
In the category "preparation for test", some students expressed that simulation was good preparation for the preclinical test, including that they could repeat procedures. "Good preparation for/in the preclinical test." "Anxiety prevention in relation to tests and communication."

In the category "recall errors", students felt that they learned from their mistakes. "Trial and error, you learn a lot from errors."

In the category "feedback", the active students were positive towards feedback from their peers and lecturer. "Repeat/get the opportunity to go through the procedure in addition to feedback afterwards and help during." "Good with feedback from peers."

Forty-two $(n=76)$ active students answered the third openended question about what should be improved or done differently, with the majority indicating that nothing should be changed whereas some provided very short comments. A few students criticized the technical equipment, primarily in regard to the sound.

\section{Effect of active participation in simulation on the preclini- cal test}

Of the 158 students registered, $155(98 \%)$ actually took the preclinical test. Of these, $125(80.6 \%)$ passed and $30(19.4 \%)$ failed. Of the 30 students failing the test, ten $(33 \%)$ were active students whereas the remaining $20(67 \%)$ were observers. Of the 125 students who passed the test, $68(54.4 \%)$ were active students whereas the remaining 57 (45.6\%) were observers. A significant difference (Fishers exact test $p<.05$ ) was seen between active students and observers in relation to the pass/fail preclinical test.

\section{Discussion}

The aim of the actual study was two-fold: to evaluate nursing students' experiences of active participation in the use of a computerized simulation manikin during first-year Bachelor's studies and to evaluate the effect of active participation in simulation by comparing active students' results with observers' results on a preclinical test.

All students were asked to prepare for simulation by reading case notes and studying current practical procedures. Q2 (Prepared for the day) scored 3.42 (mean), which indicated that students could have been more prepared. It is important to be well prepared for a simulation situation. ${ }^{[34]}$ According to Husebø, Rystedt and Friberg, ${ }^{[35]}$ during briefing it is important to focus on students' demonstrated understanding. This was an aspect we did not take into account.

The nursing students in this study experienced simulation as being beneficial $(4.43$, mean) and requested more simulation scenarios with a computerized simulation manikin during their education, also seen in the results of an earlier study. ${ }^{[23]}$ Active students experienced simulation as being beneficial, which coincides with results from other studies. ${ }^{[16,17,23]} \mathrm{Sim}$ ulation with a high-fidelity manikin is considered a beneficial learning method. ${ }^{[2,36,37]}$ Cant and Cooper ${ }^{[38]}$ found that nursing students can develop and analyze their knowledge through simulation as a learning method. In this study, only a few students experienced simulation as being beneficial to a small extent. While we cannot fully explain this result, some students may have low self-efficacy, ${ }^{[22]}$ which affects performance in regard to a specific task. A close correlation $(0.701 ; p<.01)$ existed between students who answered that the day's learning goals were realized and that expectations of the day were met. A moderate correlation also existed between students who answered that they were satisfied with the pedagogical learning method and that the day's learning goals were realized $(0.424 ; p<.01)$ or that expectations of the day were met $(0.469 ; p<.01)$. Replies to the open-ended questions revealed that students experienced simulation as being a good learning method, indicating that simulation could be useful as a pedagogical learning method. Dearmon, Graves, Hayden, Mulekar, Lawrence, Jones, Smith and Farmer ${ }^{[39]}$ support this finding, having concluded in their study that simulation-based orientation was very useful in preparing nursing students for practice.

Students considered feedback from their peers and lecturer in plenum to be helpful (see Table 1). Alinier et al. ${ }^{[1]}$ concluded that students should regularly receive feedback to ensure that they take away from an experience what it was that they were expected to learn, and we concur. Johannesson, Olsson, Petersson \& Silèn ${ }^{[40]}$ ascertained that feedback was one of the most prominent learning features when computer simulation is used as a learning method. Gibbs and Simpson ${ }^{[41]}$ found that feedback should lead to learning but that it is important that feedback is given quickly enough and is focused on performance so that it can be used to help students improve their performance. The results from our study show that feedback was useful for students, which could imply that from an educational perspective feedback is essential for learning. The students also considered reflection during debriefing as being beneficial. Debriefing that includes reflections on students' actions and needs facilitates processing, learning and mastering. ${ }^{[42]}$

In that we found a significant difference $(p<.05)$ between the two, active participation would seem useful with regard to passing the preclinical test. These results are in keeping with other international simulation nursing studies that find that high-fidelity simulation enhances scores on both knowledge and skills exams ${ }^{[43]}$ and leads to higher knowledge scores. ${ }^{[44]}$ 
Cant and Cooper ${ }^{[38]}$ described twelve studies that used an experimental or quasi-experimental design, all of which all found simulation to be a valid teaching/learning strategy; gains in knowledge, critical thinking, ability, satisfaction and competence were also seen in half of these studies. Still, Kaplan, Abraham and Gary ${ }^{[45]}$ found in their study no significant differences between active participation and mere observation during simulation in regard to test scores.

To pass the preclinical test, the students must demonstrate nursing that promotes both patients' well-being and safety and students' own personal safety, and they must exhibit professional knowledge relevant to the procedure. In 2010, prior to the introduction of computerized simulation at the University College, the preclinical test failure rate was $27 \%$. Following the introduction of simulation, the failure rate has fallen to $14 \%-19 \%$, which can indicate that the use of computerized patient simulation is beneficial. Nursing education requires knowledge from different domains: scientific, practical and ethical knowledge. ${ }^{[46]}$ During preclinical skill training, students must work with all three knowledge domains, including pertinent ethical aspects. Through simulation, nursing students train these knowledge domains and can practice in a safe environment without harming a patient. Using patients as "guinea pigs" in professional training can no longer be justified. ${ }^{[4]}$ According to McCaughey and Traynor, ${ }^{[36]}$ the skills acquired during simulation are transferred to the clinical setting, thus promoting patient care.

Yuan et al. ${ }^{[43]}$ concluded that it is necessary to conduct more high quality randomized controlled trials with larger sample sizes to determine the effect of high-fidelity simulation on students' performance. We accordingly agree that further studies are needed to develop students' possibilities to participate in and/or observe simulation scenarios with a computerized simulation manikin.

\section{Methodological considerations}

It is possible to reach many respondents in a short time through use of a questionnaire. In this study a relative large number of students from one University College were going to experience a simulation situation and, therefore, using a questionnaire was advantageous. The high response rate was probably achieved because the questionnaire was distributed immediately after simulation and debriefing. Also, one of the study researchers had taught during the course of the year and was well known, which may have influenced participation in the study and questionnaire responses.

The summative questionnaire was specifically developed for an earlier study. ${ }^{[23]}$ Changes in the questionnaire were made to suit this study. One strength of this study may be that the questionnaire has been used before. Two further strengths are that students were given the opportunity to comment on each question and that the questionnaire included two openended questions where students could emphasize what was especially good with simulation or indicate what could be improved or done differently.

The researchers together conducted the inductive content analysis of the responses from the two open-ended questions, and that may be a strength. It would appear to be beneficial to subject the material to different views and, in this manner, reveal different angles and focus, which may improve the utilization of the material. ${ }^{[31]}$

This is a case study from one University College, and a larger study needed to get results that are more reliable.

\section{Conclusion}

Nursing students experienced simulation with a computerized manikin during their professional learning as being beneficial, including feedback from peers in plenum, feedback from lecturers in plenum and reflection during debriefing. The results of this study also indicated that active participation in a simulation situation can help students pass their preclinical test.

\section{CONFLicts OF INTEREST Disclosure}

The author declares that there is no conflict of interest statement.

\section{REFERENCES}

[1] Alinier G, Hunt B, Gordon R, et al. Effectiveness of intermediatefidelity simulation training technology in undergraduate nursing education. Journal of Advanced Nursing. 2006; 54(3): 359-369. PMid:16629920 http://dx.doi.org/10.1111/j.1365-2648. 2006.03810.x

[2] Baillie L, Curzio J. Students' and facilitators' perceptions of simulation in practice learning. Nurse Education in Practice. 2009; 9(5): 297-306. PMid:18842463 http://dx.doi.org/10.1016/j.nep

Published by Sciedu Press r.2008.08.007

[3] Hawkins K, Todd M, Manz J. A Unique Simulation Teaching Method. Journal of Nursing Education. 2008; 47(11): 524-527. PMid:19010053 http://dx.doi.org/10.3928/01484834-200 81101-04

[4] Haidar E. Clinical simulation: a better way of learning? Nursing management. 2009; 16(5): 22-23. http://dx.doi .org/10.7748 $/ \mathrm{nm} 2009.09 \cdot 16 \cdot 5 \cdot 22 . c 7219$

[5] Dolonen K. Simulering viktig i undervisningen. [Simulation impor- 
tant in education] Sykepleien. 2009.

[6] Prescott S, Garside J. An evaluation of simulated clinical practice for adult branch students. Nursing Standard. 2009; 23(22): 35-40. PMid:19263960 http://dx.doi.org/10.7748/ns2009.02.23. 22.35. c6776

[7] Leonard B, Shuhaibar E, Chen R. Nursing Student Perceptions of Intraprofessional Team Education Using High-Fidelity Simulation. Journal of Nursing Education. 2010; 49(11): 628-631. PMid:20669872 http://dx.doi .org/10.3928/01484834-201 00730-06

[8] Gantt TL, Webb-Corbett R. Using Simulation to Teach Patient Safety behaviors in Undergraduate Nursing. Journal of Nursing Education. 2010; 49(1): 48-51. PMid:19810666 http://dx.doi.org/10. 39 28/01484834-20090918-10

[9] Gundrosen S, Engesnes H. Medical simulation - a meeting between education and the field of practice. Inspira. 2010; 3(10): 14-18.

[10] Ricketts B. The role of simulation for learning within pre-registration education - A literature review. Nurse education Today. 2011; 31(7): 650-654. PMid:21074297

[11] Cioffi J. Clinical simulations: development and validation. Nurse education Today. 2001; 21(6): 477-486. PMid:11466011 http: //dx.doi.org/10.1054/nedt.2001.0584

[12] Harder N. Use of simulation in Teaching and Learning in Health Sciences: A Systematic Review. Journal of Nursing Education. 2010; 49(1): 23-8. PMid:19731886 http://dx.doi.org/10.3928/014 84834-20090828-08

[13] Moule P, Wilford A, Sales R, et al. Student experiences and mentor views of the use of simulation for learning. Nurse Education Today. 2008; 28(7): 790-797. PMid:18479785 http://dx.doi.org/10 1016/j.nedt.2008.03.007

[14] Wotton K, Davis J, Botton D, et al. Third-Year Undergraduate Nursing Students' Perceptions of High-Fidelity Simulation. Journal of Nursing Education. 2010; 49(11): 632-40. PMid:20795614 http://dx.doi.org/10.3928/01484834-20100831-01

[15] Berragan L. Simulation: An effective pedagogical approach for nursing? Nurse Education Today. 2011; 31(11): 655-659. http: //dx.doi.org/10.1016/j.nedt.2011.01.019

[16] Gates GM, Parr BM, Hughen EJ. Enhancing Nursing Knowledge Using High-Fidelity Simulation. Journal of Nursing Education. 2012 51(1): 189-209. PMid:22085206 http://dx.doi.org/10.3928 /01484834-20111116-01

[17] Lewis R, Strachan A, Smith MM. Is High Fidelity Simulation the Most Effective Method for the Development of Non-Technical Skills in Nursing? A Review of the Current Evidence. The open Nursing Journal. 2012; 9(6): 82-89. PMid:22893783 http://dx.doi .org /10.2174/1874434601206010082

[18] Rhodes M, Curran C. Use of the Human Patient Simulator to Teach Clinical Judgment Skills in a Baccalaureate Nursing Program. CIN: Computer, Informatics, Nursing. 2005; 23(5): 256-262. http://dx.doi.org/10.1097/00024665-200509000-00009

[19] Strand I, Nåden D, Slettebø A. Students Learning in a Skills Laboratory. Vård i Norden. 2009; 93(29): 18-22.

[20] Garett BM, MacPhee M, Jackson C. Implementing high-fidelity simulation in Canada: Reflections on 3 years of practice. Nurse Education Today. 2011; 31(7): 671-676. PMid:21075494 http: //dx.doi.org/10.1016/j.nedt.2010.10.028

[21] Kameg K, Haward VM, Clochesy J, et al. The Impact of High Fidelity Human Simulation on Self- Efficacy of Communication Skills. Issues in Mental Health Nursing. 2010; 31(5): 315-323. PMid:20394477 http://dx.doi.org/10.3109/01612840903420331

[22] Bandura A. Self-efficacy, the exercise of control. New York; 1997.
[23] Flo J, Flaathen EK, Fagerström L. Simulation as a learning method in nursing education - A case study of students' learning experiences during use of computer-driven patient simulators in preclinical studies. Journal of Nursing Education and Practice. 2013; 3(8): 138-48. http://dx.doi.org/10.5430/jnep.v3n8p138

[24] Ministry of Education. Act Relating to Universities and University Colleges, 2005.

[25] Ministry of Education. Curriculum Framework for Nursing Education, 2008.

[26] Ministry of Education. White Paper no. 27. Do your duty - Claim your rights.

[27] EU directiv. Directive on the Recognition of Professional Qualifications. 2005.

[28] Dieckmann P. Using simulations for education, training and research. Lengerich: Pabst Science Publishers; 2009.

[29] Polit D, Beck C. Nursing research: principles and methods. Lippincott Williams \& Wilkins; Philadelphia; 2004.

[30] Elo S, Kyngäs H. The qualitativ content analysis process. Journal of Advanced Nursing. 2007; 62(1): 107-115. PMid:18352969 http://dx.doi.org/10.1111/j.1365-2648.2007.04569.x

[31] Malterud K. Kvalitative metoder i medisinsk forskning [Qualitative Methods in Medical Research]. Oslo: Universitetsforlaget; 2011.

[32] Pallant J. 4th ed. SPSS - Survival manual: a step by step guide to data analysis using SPSS. McGraw- Hill Open University Press; 2010.

[33] Personal Data Regulation. Personopplysningsforskriften. 2000.

[34] Kiat TK, Mei TTT, Nagammal S, et al. A review of learners' experience with simulation based training in nursing. Singapore Nursing Journal. 2007; 34(4): 37-43.

[35] Husebø SE, Rystedt H, Friberg F. Educating for teamwork - nursing students' coordination in simulated cardiac arrest situations. Journal of Advanced Nursing. 2011; 67(10): 2239-2255. PMid:21466575 http://dx.doi.org/10.1111/j.1365-2648.2011.05629.x

[36] McCaughey SC, Traynor KM. The role of simulation in nurse education. Nurse Education Today. 2010; 30(8): 827-832. PMid:20483188 http://dx.doi.org/10.1016/j.nedt.2010.03.005

[37] Sheets WI, Ganley JB. Integrating Simulation into a Foundational Gerontological Nursing Coure. Journal of Nursing Education. 2011; 50(12): 689-92. PMid:21919427 http://dx.doi.org/10.3928 /01484834-20110916-01

[38] Cant RP, Cooper SJ. Simulation-based learning in nurse education: systematic review. Journal of Advanced Nursing. 2009; 66(1): 3 15. PMid:20423432 http://dx .doi .org/10.1111/j.1365-264 8.2009.05240.x

[39] Dearmon V, Graves R, Hayden S, et al. Effectiveness of SimulationBased Orientation of Baccalaureate Nursing Students Preparing for Their First Clinical Experience. Journal of Nursing Education. 2013; 52(1): 29-38. PMid:23230885

[40] Johannesson E, Olsson M, Petersson G, et al. Learning features in computer simulation skills training. Nurse Education in Practice. 2010; 10(5): 268-273. PMid:20015690 http://dx.doi.org/10. 1016/j.nepr.2009.11.018

[41] Gibbs G, Simpson C. Condition under which assessment supports students' learning. Learning and Teaching in higher Education. 2004; 1(1): 1-31.

[42] Tveiten S. Pedagogikk i sykepleiepraksis [Pedagogy in nursing]. 2008.

[43] Yuan BH, Williams AB, Fang BJ, et al. A systematic review of selected evidence on improving knowledge and skills through highfidelity simulation. Nurse Education Today. 2012; 32(3): 294-98. http://dx.doi.org/10.1016/j.nedt.2011.07.010 
[44] Shinnick MA, Woo M, Evangelista LS. Predictors of Knowledge Gains Using Simulation in the Education of Prelicensure Nursing Students. J Prof Nurs. 2012; 28(1): 41-46.

[45] Kaplan GB, Abraham C, Gary R. Effect of participation vs Observation of a Simulation Experience on Testing Outcomes: Implication for Logistical Planning for a School of Nursing. International Journal of Nursing Education Scholarship. 2012; 9(1): 1-15.
http://dx.doi.org/10.1515/1548-923X. 2398

[46] Fagerström L. Den tredimensionella kunskapssynen som epistemologisk grundsyn. I: Avancerad klinisk sjuksköterska. Fagerström, L. Studentlitteratur, Lund. 2010.

[47] Gaba D. The future vision of simulation in health care. Quality and safety in Health care. 2004; 13(Suppl 1): 2-10. http: //dx.doi.o rg/10.1136/qshc. 2004.009878 